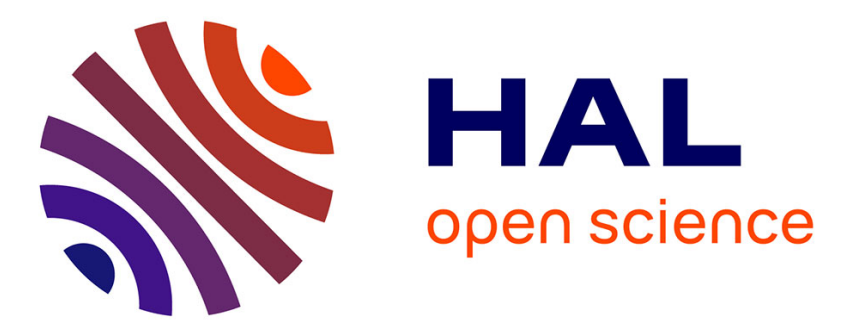

\title{
Atomic layer deposition (ALD) on inorganic or polymeric membranes
}

Matthieu Weber, Anne Julbe, Sang Sub Kim, Mikhael Bechelany

\section{To cite this version:}

Matthieu Weber, Anne Julbe, Sang Sub Kim, Mikhael Bechelany. Atomic layer deposition (ALD) on inorganic or polymeric membranes. Journal of Applied Physics, 2019, 126 (4), pp.041101. 10.1063/1.5103212 . hal-02278784

\section{HAL Id: hal-02278784 \\ https://hal.umontpellier.fr/hal-02278784}

Submitted on 23 Nov 2020

HAL is a multi-disciplinary open access archive for the deposit and dissemination of scientific research documents, whether they are published or not. The documents may come from teaching and research institutions in France or abroad, or from public or private research centers.
L'archive ouverte pluridisciplinaire HAL, est destinée au dépôt et à la diffusion de documents scientifiques de niveau recherche, publiés ou non, émanant des établissements d'enseignement et de recherche français ou étrangers, des laboratoires publics ou privés. 


\title{
Atomic Layer Deposition (ALD) on inorganic or polymeric membranes
}

Matthieu Weber, ${ }^{1}$ Anne Julbe, ${ }^{1}$ Sang Sub Kim, ${ }^{2, *}$ and Mikhael Bechelany ${ }^{1, *}$

${ }^{1}$ Institut Européen des Membranes, IEM - UMR 5635, ENSCM, CNRS, University of Montpellier, Place Eugène Bataillon, 34095 Montpellier cedex 5, France.

${ }^{2}$ Department of Materials Science and Engineering, Inha University, Incheon 22212, Republic of Korea.

*co-corresponding authors: sangsub@inha.ac.kr and mikhael.bechelany@umontpellier.fr

\begin{abstract}
Membranes can be defined as physical barriers allowing the selective transport of species. This tutorial aims to provide the basics of membrane technologies and materials, the fundamentals of the atomic layer deposition (ALD) technique, and, most importantly, to describe how to perform efficiently ALD on different membrane substrates. Membrane devices enable to considerably reduce costs and environmental impacts of many industries, and there is a constant need to improve their operational performance. Atomic layer deposition (ALD) is a deposition technique enabling the preparation of high quality thin films on extremely high aspect ratio substrates with an excellent conformality and a thickness control at the nanolevel, a unique capability. Therefore, this technology can be applied for both pore size tailoring and interface engineering in membrane structures. Certain important aspects that must be taken into consideration when carrying out ALD on these highly porous ceramic or polymeric membrane substrates will be addressed, in order to achieve a conformal coating of pore walls. Finally, this tutorial will also provide specific case studies to illustrate how ALD can be applied to various membrane devices and improve their operational performance. Thus, by providing this knowledge of ALD for membrane applications, this tutorial will permit to better exploit this emerging and growing field.
\end{abstract}




\section{Introduction}

The required drastic reduction of pollutions created by human activities represents an immense and urgent challenge. Highly efficient membrane processes could permit to considerably reduce the environmental impacts of many industries and present many advantages over traditional methods of separation, purification, and concentration for a wide diversity of compounds. ${ }^{1}$ An ideal membrane is a physical barrier allowing the selective transport of species between two media, and offering both high selectivity and permeability. Membrane technology is already widely used in various separation systems, e.g. for liquid and gas separations, purification or extraction, water desalination, organic solvent dehydration, and various environmental applications in relation with water or air treatment. ${ }^{1-5}$ Energy-related applications of membranes (i.e. energy production or energy saving by process intensification) are also increasingly developing, for example in fuel cells and catalytic membrane reactors. These novel application fields require specific characteristics from the membrane materials, such as precise pore size, thermal stability for high-temperature applications, mechanical and chemical stability, fouling resistance, sterilization ability and biocompatibility. Despite the range of available membrane materials, (relatively) easy manufacturing and highly advanced module technology, commercial ceramic and organic polymer membranes can hardly fulfil all the specific structural, microstructural and functional requirements. ${ }^{6}$ Therefore, further research on the development of up-scalable routes able to provide a fine and versatile tuning of both organic and inorganic membrane properties is required. In fact, the precise and rational design of membrane materials with controllable pores sizes and surface chemistry at the nanoscale is an extremely attractive strategy for expanding the range of membrane performance.

Atomic Layer Deposition (ALD) is a vacuum deposition technique based on self-limiting chemistry, allowing for the preparation of thin films with a sub-nanometer thickness control and excellent conformality, even on high aspect ratios substrates. ${ }^{7-10}$ The precise control of the nature and chemistry of the membrane pore surface is a key challenge. Because of both conformal coating and excellent thickness control at the nanoscale, and because of the wide range of materials that can be 
deposited, the ALD route lately became very valuable for membrane science. For example, ALD has been applied i) to tune the surface properties of porous structures, thus modifying their interfacial properties, and also ii) to define pore diameters at the nanoscale, in order to increase membrane selectivity. ${ }^{11-14}$ Recently, our group published an overview of ALD studies focusing on membrane applications. This review reported the many studies in which ALD has been applied for the tuning of inorganic, organic, hybrid and composite membranes properties and performance. The reader interested in this upcoming and growing field of research is referred to Reference. ${ }^{14}$

This tutorial aims first to provide the basics of membrane technologies and materials, as well as the fundamentals of ALD. Next, the focus will be on the description on how to perform ALD efficiently on different membrane substrates, either inorganic or polymer supports. This tutorial will not list the many studies carried out in this field, but instead addresses certain important aspects regarding key factors that must be taken into consideration when performing ALD on the peculiar porous membrane substrates. In fact, when considering practical ALD experiments, it is important to realize that membranes with high aspect ratio pores require an important tuning of the applied process parameters. ALD is based on sequential pulses of the precursor and coreactant molecules. Typically, when performing ALD on/in porous membranes, the exposure times of these pulses have to be considerably extended in comparison with flat non-porous supports.

Additionally, specific examples will illustrate how this route can be applied to enhance the performance of membranes. Thus, by providing the basics of the techniques and selected examples, this tutorial will facilitate the rational use of this technology towards membrane applications.

\section{Basics on membranes and membrane processes:}

A permselective membrane is a physical barrier enabling the selective transport of certain species. The separation process is achieved by enabling species/molecules to pass through the membrane as a result of a driving force. Most transport processes occur because of a difference in chemical potential (pressure and concentration contribute to the chemical potential). An electrical or 
electrochemical gradient can also act as a driving force. The degree of selectivity of a porous membrane directly depends on the characteristics of its pores (size, surface charge and chemistry). ${ }^{1-5}$ Porous membranes can be classified according to the size of their pores, as recommended by IUPAC (Table 1). ${ }^{15}$

Table 1: Membrane classification by pore type, according to IUPAC..$^{15}$

\begin{tabular}{ccc}
\hline Pore type & Pore size $(\mathbf{n m})$ & Typical membrane applications \\
\hline Micropores & $<2$ & Nanofiltration (NF), pervaporation (PV), vapor permeation \\
& $2-50$ & (VP), gas separation (GS) \\
\hline Mesopores & $>50$ & Ultrafiltration (UF) \\
\hline Macropores & Microfiltration (MF), Ultrafiltration (UF) \\
\hline
\end{tabular}

Each specific membrane application requires specific pore sizes adapted to control the transport of the considered species/molecules. For example, macropores enable the filtration of bacteria, mesopores separate most of the viruses, and micropores can separate antibiotics, ions or small gas molecules. In liquid filtration, the required transmembrane pressure increases when the membrane pore size decreases (from few bars for macroporous membranes to a few dozens of bars for microporous membranes). Dense membranes also exist, and are mainly used for the separation of species which are soluble within the membrane itself (small molecules like water, gases...). Dense membranes are typically used for water desalination by reverse osmosis (RO), for liquid mixture separations by pervaporation or for gas separation.

The standard characteristics of a membrane are its permeability (flux passing through), and its selectivity (selectivity coefficient or rejection rate). An ideal membrane presents both a high permeability and selectivity. Among the terms commonly used in membrane science are included: the feed, the permeate, the retentate and the fouling. The feed of a membrane represents the initial fluid mixture to be concentrated or fractionated. The permeate is the filtrate (the liquid/gas passing through the membrane) and the retentate is the retained liquid/gas fraction. Figure 1 is a schematic representation of a typical membrane process and associated nomenclature. Membrane fouling can 
be defined as the accumulation of feed components (e.g. organic or mineral particles or dissolved species, colloids, proteins, microbiological organisms) at the membrane surface and/or within the membrane pores, causing a flux decline during the filtration operation.

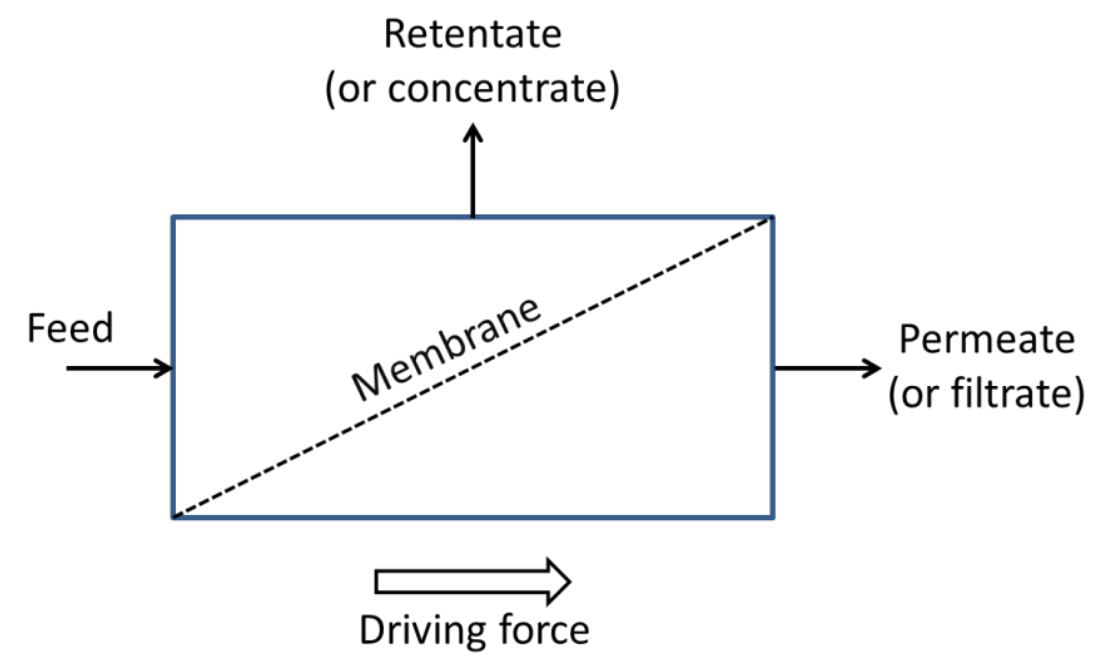

Figure 1: Schematic representation of a membrane process, showing the feed, the permeate and the retentate.

The permeability $(\mathrm{k})\left(\mathrm{m} \cdot \mathrm{s}^{-1} \cdot \mathrm{Pa}^{-1}\right)$ of a membrane is given by the equation (1):

$$
k=\frac{F}{\Delta P}
$$

where $\mathrm{F}$ is the flux rate and $\Delta \mathrm{P}$ is the transmembrane pressure.

Considering the microfiltration (MF) of water at $20^{\circ} \mathrm{C}$, the permeability would be in the range of $10^{-9}$ $\mathrm{m} \cdot \mathrm{s}^{-1} \cdot \mathrm{Pa}^{-1}$, whereas values in the range of $10^{-10} \mathrm{~m} \cdot \mathrm{s}^{-1} \cdot \mathrm{Pa}^{-1}$ and $10^{-12} \mathrm{~m} \cdot \mathrm{s}^{-1} \cdot \mathrm{Pa}^{-1}$ are typically obtained for UF and NF, respectively. ${ }^{16}$ As the permeation flux increases with the operating temperature, it is important to control this parameter during membrane processing. 
The membrane selectivity can be characterized by the retention rate (or rejection rate) of a given species (RR in \%), which is given by the equation (2).

$$
R R=1-\frac{C p}{\triangle P C 0}(2)
$$

Where $C_{0}$ is the concentration of the considered species in the feed, and $C_{p}$ the concentration of the considered species in the permeate. Typically, in UF, the membrane efficiency is characterized by the molecular weight cut-off, which can be defined as the lower limit of solute molecular weight $\left(\mathrm{M}_{\text {wi }}\right)$ for which the rejection is $>90 \%$ (Figure 2).

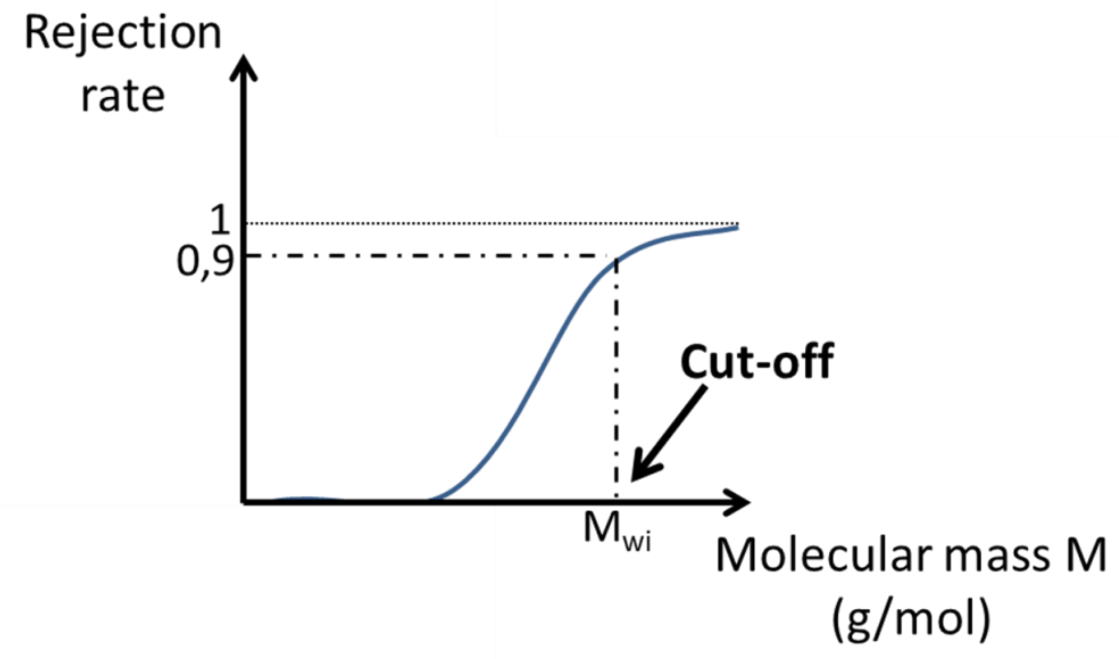

Figure 2: Schematic illustration of an experimental curve used for determination of the molecular weight cut-off $\left(\mathrm{M}_{\mathrm{wi}}\right)$ for an UF membrane.

This molecular weight cut-off is specific to UF membranes and strongly sensitive to the selected type of model solute series (shape, flexibility...), to membrane/solute interactions, to concentration polarization effects, pore blocking and fouling phenomena. The cut-off concept can also be applied to characterize NF membranes ${ }^{17}$ but can hardly be used for MF membranes as the variety of species retained during a MF process (fungi, bacteria, particles) cannot be defined only by their molecular 
mass. MF membranes are usually characterized by their mean pore size ( $>50 \mathrm{~nm})$ or pore size distribution, which can be determined experimentally by e.g. permporometry. This type of membranes usually serves as a pre-treatment for other separation processes such as ultrafiltration, and is typically applied to separate microorganisms and suspended particles, colloids or oil droplets, from process liquids.

Different separation mechanisms can be involved in a membrane separation operation. The size exclusion mechanism operates in most porous membranes, when their pore dimensions are of such a size that only certain species can selectively pass. A selective retardation by the pores (pore flow) can occur when pore sizes are close to the sizes of the species. Competitive interactions of the species to be separated with the pore surface is also a key separation mechanism in microporous membranes and differences in the diffusion rates of species can also contribute to increase the membrane separation efficiency.

The transport of species through dense membranes is based on the solution-diffusion mechanism. The species to be separated adsorb (eventually dissociate) on the membrane surface, dissolve into the bulk membrane material, migrate by molecular (or ion) diffusion across the membrane, and reemerge (recombine) on the other side. This is for example the case for $\mathrm{H}_{2} / \mathrm{CO}_{2}$ or $\mathrm{H}_{2} / \mathrm{CH}_{4}$ separation with dense palladium-based membranes, which are only permeable to $\mathrm{H}_{2}$.

Despite the improved performance of modern membrane devices, important challenges are remaining in relation with the limited rejection rates for new/emerging pollutants and microcontaminants (e.g. small soluble organics), membrane stability in harsh environments (e.g. steam, sulfur compounds) but also concentration polarization effects and its consequences : osmotic effects or fouling which are critical issues for the efficiency of membrane processes.

Concentration polarization and fouling ${ }^{18,19}$ result from the accumulation of dispersed or solubilized matter (retained species) at the fluid/membrane interface. These high concentrations of accumulated species reduce the membrane permeability by generating an osmotic counter-pressure. Fouling is the direct consequence of the accumulation of matter at the fluid/membrane interface 
and/or within the membrane pores and is inherent to all the membrane processes. Fouling creates an additional resistance to the permeate flow and yields strong flux permeation decay along the processing time. Several models have been developed to assess membrane fouling and quantify its dependence on the operating parameters of cross-flow velocities and transmembrane pressure (film theory and mass transfer coefficients). ${ }^{19}$ A simple model based on the application of Darcy's law (equation 3), describing the flux through a membrane, can be applied to estimate the various fouling resistances during filtration operation. ${ }^{20}$

$$
J=\frac{\Delta P}{\mu(R m+R c+R b)}
$$

where $\mathrm{J}$ is the permeate flux $\left(\mathrm{L} / \mathrm{m}^{2} \cdot \mathrm{s}\right), \mu$ is the dynamic viscosity (bar.s), $\Delta \mathrm{P}$ is the transmembrane pressure (bar), Rtot is the total membrane filtration resistance $\left(\mathrm{m}^{-1}\right), \mathrm{Rm}$ is the intrinsic membrane filtration resistance $\left(\mathrm{m}^{-1}\right), \mathrm{R}_{c}$ is the reversible resistance caused by the cake layer $\left(\mathrm{m}^{-1}\right)$, and $\mathrm{R} b$ is the irreversible resistance related to pore blocking $\left(\mathrm{m}^{-1}\right)$.

Fouling phenomena can be (partially) reversible or not and their limitation implies higher productivity, less cleaning and longer membrane life, thus reducing operational and capital costs. Different strategies (fouling resistance, fouling release or fouling attack) can be used to struggle scaling, biofouling, and non-specific organic fouling. In addition to the optimization of membrane module design, fluid management and cleaning cycles, strong reduction of concentration polarization and fouling issues can derive from nanoengineering of membranes surface/interfaces. This is a very active field of research. ${ }^{21}$

Synthetic membranes can be based on inorganic, organic, hybrid or composite materials. Different parameters are keys for the manufacturing of effective membranes: the membrane material intrinsic properties, but also the complexity of the membrane design, the module configuration and the upscaling possibility.

Due to their easy manufacturing in compact, large scale and low cost systems, their attractive selectivity, relative stability and commercial availability with tunable properties, synthetic polymers 
are the most common materials used in industrial membrane processes. These synthetic polymers can be based on cellulose (acetate, esters or nitrocellulose), polysulfone and poly-ether sulfone (PS, PES), polydimethysiloxane (PDMS), polyacrylonitrile (PAN), polyethylene and polypolypropylene (PE, PP), polyamide (PA), polyimide (PI), polytetrafluoroethylene (PTFE), polyvinylidene fluoride (PVDF), polyvinylchloride (PVC) or poly(ethyleneterephthalate (PET), among others. Ceramic membranes, mainly based on oxides, also attracted specific attention because of several outstanding characteristics, such as high thermo-chemical and mechanical resistance adapted to harsh conditions. As the efficiency of a membrane largely depends on its pores structure and surface properties, strong research efforts is devoted to achieve optimal membrane materials for each focused applications. Membranes can be manufactured with either symmetric or asymmetric structure with a stacking of several layers presenting different pore sizes, and with different configurations (flat sheets, tubes, honeycombs, hollow fibers...). ${ }^{4}$ For example, a ceramic membrane tube (single channel) displaying a typical asymmetric (multi-layers) micro-structure is shown in Figure 3.

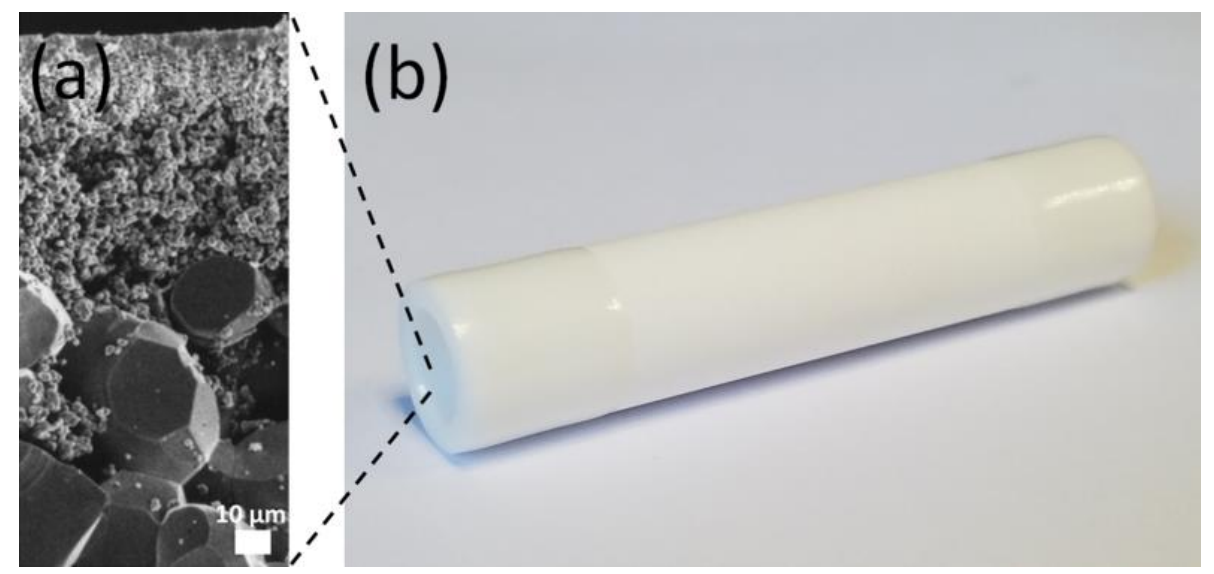

Figure 3: (a) SEM image showing the details of an alumina asymmetric microstructure, where the thin selective top-layer is supported on intermediate and support layers ( $\alpha$-alumina) with larger pore sizes. (b) Ceramic membrane tube ( $\alpha$-alumina, single channel, Pall Exekia) presenting an asymmetric microstructure. 
In membrane processes, two operational modes can be used:

- Dead-end mode where the feed applied to the membrane passes through it completely,

- Cross-flow mode where the feed is passing through with a cross-flow tangential to the membrane (this is the case in Figure 1).

When using the cross-flow operation mode, a continuous flushing effect operates, thus limiting fouling phenomena. This risk of fouling is higher in the dead-end filtration mode, but the recommended operation mode strongly depends on the feed properties. When fouling cannot be avoided, back flushing and/or chemical cleaning can be applied to regenerate the membrane.

Despite their numerous advantages, membranes still suffer from limitations such as irreversible fouling and/or deficient selectivity. Thus, there is a real need to explore novel routes enabling the fine tuning of membrane materials pore sizes and surface properties in order to mitigated fouling effects, improve selectivity and extend the range of membranes application and performance. The control and fine tuning of the membrane pore surface is very challenging. Not only because of both conformal coating and excellent thickness control at the nanoscale, but also because of the wide range of materials that can be deposited, the ALD technique appears as a promising route and can be applied to control the dimensions and functionalization of porous membranes.

\section{Fundamentals of ALD}

ALD is a vapor phase technique enabling the preparation of thin films through the sequential use of self-terminating gas-solid reactions. This technology is a chemical vapor deposition (CVD) derived technique, suitable for the manufacturing of high quality inorganic material layers with a thickness controllable at the (sub)nanoscale. ${ }^{7-10}$ ALD research started already in the 1950 s in the former USSR (Union of Soviet Socialist Republics), ${ }^{22,23}$ and the technique has been patented in $1977 .{ }^{23}$ The semiconductors industry became interested in ALD in the $1990 \mathrm{~s},{ }^{23,24}$ and the technique since became a key enabling technology for microelectronic devices fabrication. ${ }^{25}$ 
In the ALD method, the process of alternating self-terminating chemical reactions between precursor molecules and a solid substrate surface is used to deposit thin films in a layer by layer fashion. Briefly, the growth of material layers by ALD consists of repeating the following four steps:

- A self-terminating reaction of precursor molecules with surface species,

- A purge or evacuation to remove both the non-reacted reactants and gaseous reaction byproducts,

- A self-terminating reaction of the second reactant or another treatment to activate the surface, again for the reaction of the first reactant.

- A purge or evacuation.

These 4 steps are defined as an ALD reaction cycle, which can be divided in two half cycles (of a "full" ALD cycle). ${ }^{8}$ A schematic representation of an ALD cycle is illustrated in Figure 4. In each cycle, a given amount of material is added to the surface, which is typically referred as the growth per cycle (GPC). To obtain a defined material layer, the ALD reaction cycles are repeated until the desired amount of material has been deposited.

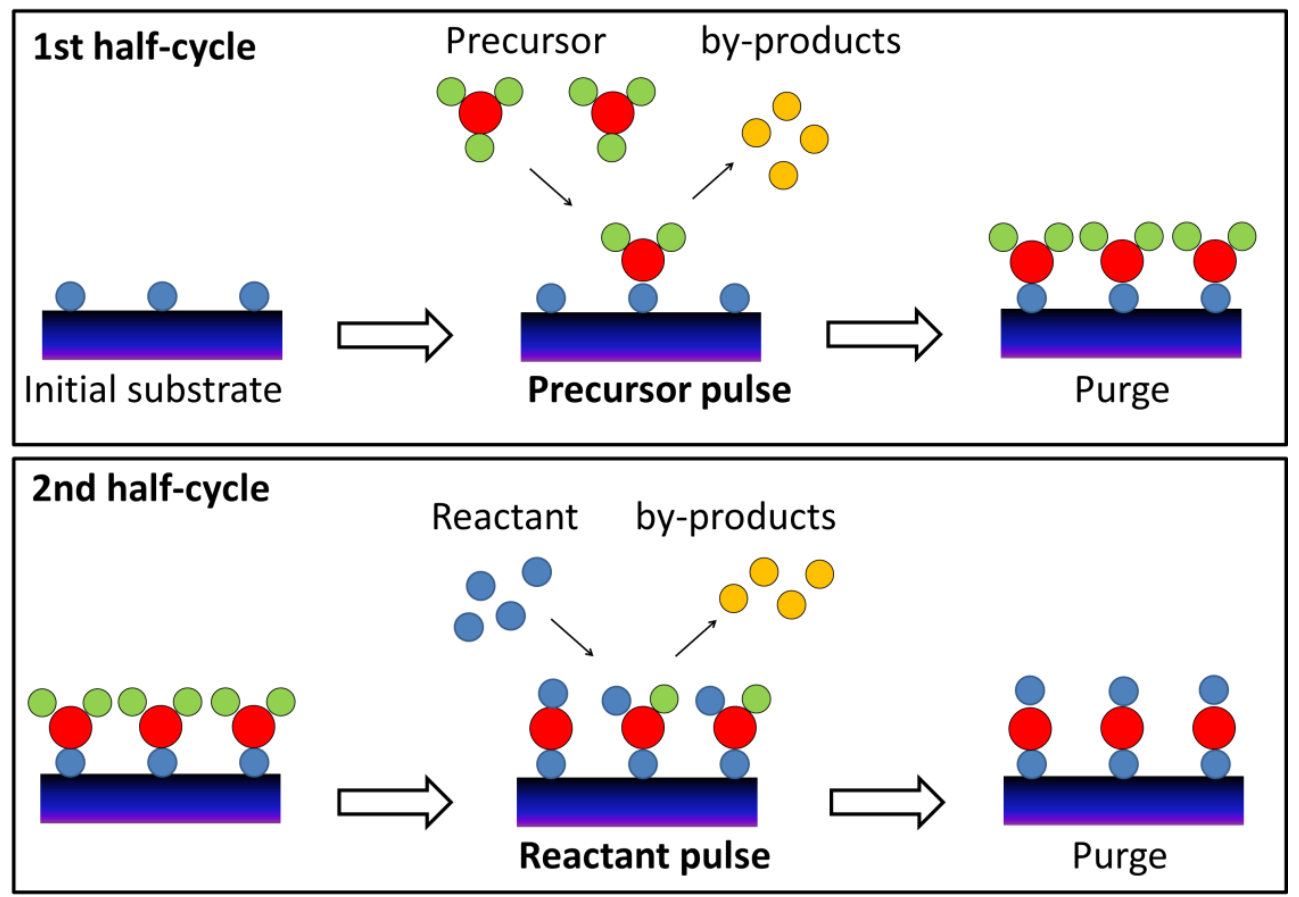


Figure 4: Schematic representation of an ALD cycle. In the first half-cycle, the substrate is first exposed to a precursor, and then purged. In the second half-cycle, the surface is exposed to a reactant and again purged.

The use of self-terminating reactions means that the ALD route is a surface-controlled process. Therefore, thanks to this surface reaction control, ALD-grown films are extremely conformal and uniform in thickness, ${ }^{7-10}$ in sharp contrast to other techniques controlled by the flux of reactants such as physical vapor deposition (PVD). In fact, no other thin film deposition method can even approach the conformality achieved by ALD on high aspect ratio structures. Typically, ALD processes occur at relatively low temperatures (from room temperature to $300^{\circ} \mathrm{C}$ ), which enable applications on surface thermally sensitive substrates as well. Consequently, ALD-grown materials can be applied to a large range of applications, from biosensing ${ }^{26}$ to microelectronics, ${ }^{25,27}$ and from nanocatalysts ${ }^{28}$ to solar photovoltaics. ${ }^{29}$

\subsection{Surface chemistry and ALD precursors}

Since ALD is based on surface reactions, it is important to define two types of interaction phenomena able to occur between a fluid (gas or liquid species, adsorbate) and a solid surface (adsorbent): physisorption (or physical adsorption) and chemisorption (or chemical adsorption). Physisorption is characterized by relatively low interaction energies $\left(<20 \mathrm{~kJ} \mathrm{~mol}^{-1}\right)$, such as Van der Waals forces for example. Thus adsorption rates are fast and the typical temperature of an ALD process is usually sufficient to desorb physisorbed species. Higher energy $\left(60-120 \mathrm{~kJ} \cdot \mathrm{mol}^{-1}\right)$ is involved in the case of chemisorption, and the adsorbed reagents form chemical bonds with the surface. Similarly to physisorption, the required amount of energy depends on both the type of reacting species and the nature of the surface. Chemisorption involves activation energy and leads most of the time to the dissociation of the gaseous precursor molecules. At the typical temperature of an ALD process, physisorbed molecules are desorbed, whereas chemisorbed reagents remain at the surface and 
participate to the film growth. ALD uses self-terminating chemical reactions between precursor molecules, which include at least one of the elements required in the film composition and relevant ligands. The precursor design needs careful balancing between volatility, thermal stability and reactivity-the key properties of ALD precursors.

Overall, to be used as an ALD precursor, a molecule must have the appropriate thermogravimetric characteristics, i.e. to be volatile at a temperature below the deposition temperature. In addition, the precursor molecules should:

- not decompose, neither in storage conditions nor during their vaporization, nor at the deposition temperature;

- have a suitable reactivity to permit the saturated and irreversible chemical reaction to occur on the desired surface area with fast kinetics;

- permit the adsorption of the reactant;

- generate inert or non-reactive by-products;

- be easy to handle (limited toxicity, non-corrosive, etc.).

These characteristics are brought to the precursor through its ligands, which obviously play a crucial role. Different classes of precursors can be considered for ALD, either inorganic (elemental compounds, halides) or organometallic (alkyl, cyclopentadienyl, alkoxides, $\beta$-diketonates, amides, amidinates...), each having its advantages and drawbacks in terms of reactivity, stability, film impurities and generated byproducts. ${ }^{30}$

\subsection{Deposition temperature - The ALD window}

The deposition temperature is a key parameter of an ALD process, as it strongly affects the film growth per cycle (GPC). The relationship between the GPC and the deposition temperature, illustrating the "ALD window" concept, is shown in Figure 5. 


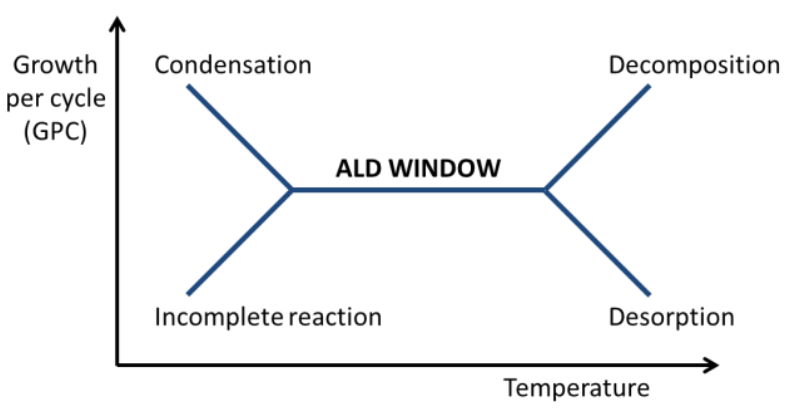

Figure 5: Schematic representation of the relationship between the GPC and the deposition temperature, illustrating the "ALD window" concept.

Different situations can occur, according to the deposition temperature ( $\left.T_{\text {dep }}\right)$ :

- at high $T_{\text {dep, }}$ an increasing GPC can be observed due to precursor decomposition at the surface before reacting with the second reactant;

- at high $T_{\text {dep, }}$ a decreasing GPC can be sometimes witnessed as well, due to precursor desorption, reduction of the number of surface species or sublimation of the deposited material;

- at low $T_{\text {dep }}$, a decreasing GPC indicates that more than one monolayer is adsorbed or that condensation occurs;

- at low $T_{\text {dep, }}$ an increasing GPC can also be observed, revealing low reaction rates due to activation energy limitation and too long reaction time compared to the duration of an ALD cycle.

Within the temperature range where the GPC is constant, the deposition rate does not depend on the temperature but only on the density of available reactive sites at the support surface and on the degree of surface saturation with the adsorbed precursor molecules. In this temperature range, called the "ALD window", the deposition rate is constant and the ALD per say occurs (film growth).

The understanding of the thermodynamics of gaseous compounds can also provide very valuable information to understand the thermal behavior of the gaseous precursors and the growth 
mechanisms. In fact, the knowledge of thermodynamics can be used to model how the precursor source evolves, and what phenomena are taking place in the input lines and in the deposition chamber. Thermodynamics can be strongly dependent on the selected ALD process parameters, and are very scarcely investigated in the literature. However, thermodynamic modeling, based on the Gibbs free-energy minimization, could be performed to simulate the nature of the species that can be present in different positions of the reactor at equilibrium, under given experimental conditions. For example, Violet et al. determined the thermal stability and behavior of organometallic precursors used for ALD deposition of $\mathrm{TaN}$ and $\mathrm{ZrO}_{2}$ layers using in-situ mass spectrometry and numerical simulations. ${ }^{31}$

\subsection{Precursor pulse and purge times - ALD saturation curves}

The determination of relevant precursor pulse and purge times is fundamental in an ALD recipe. These times must be sufficiently long to allow the saturation of the surface (pulse time) and avoid reactants mixing in gas phase (purge time), but they need to be optimized in order to avoid excessively slow deposition rates. Thus, an essential step in the development of an ALD process is the determination of the optimal pulse and purge times. For this purpose, the influence of each time value on the GPC needs to be studied (by keeping the other times constant). This leads to the socalled saturation curves (Figure 6), which represent also a key step in the development of an ALD process. Please note that the determination of such saturation times can be greatly facilitated by monitoring the film thickness in-situ. ${ }^{32,33}$ 

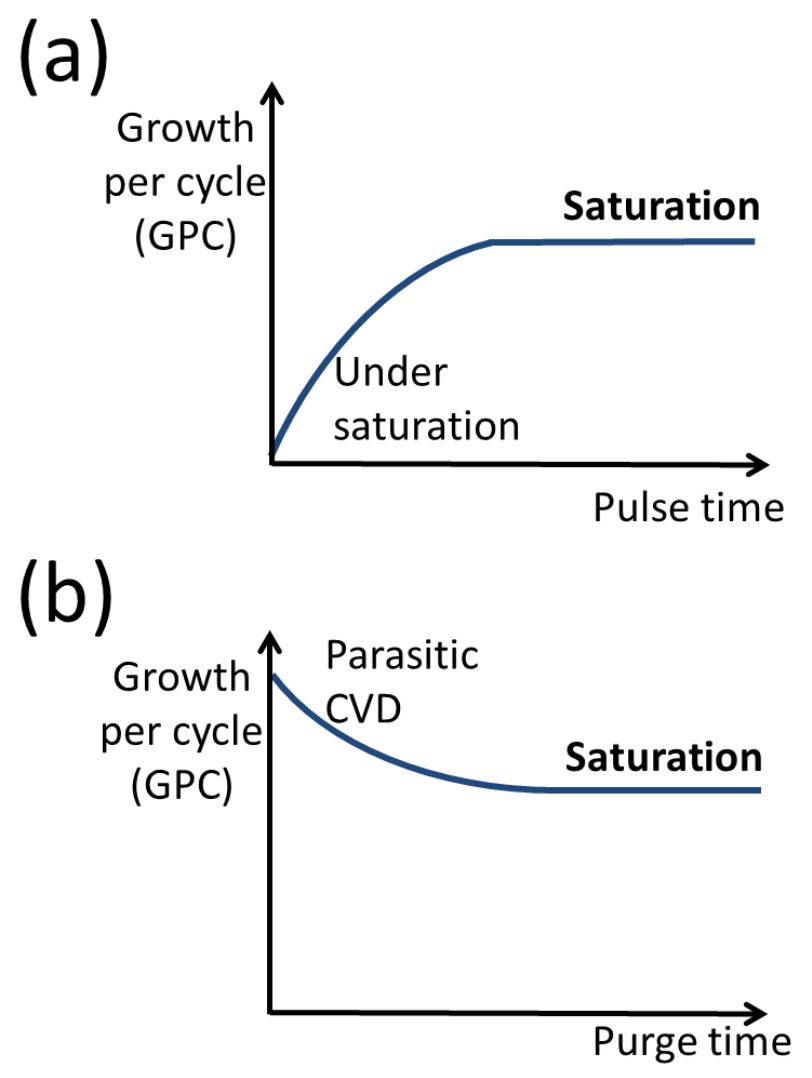

Figure 6: Schematic representation of the influence of (a) pulse and (b) purge times on the film growth rate during ALD process, the so-called saturation curves.

In general, the GPC increases with the precursor pulse time, following an under-saturation of reactive species, and then becomes independent of the pulse time when the surface is fully saturated. In the case of too short purge times, a high GPC is observed because both reactants are found simultaneously in the gas phase and a parasitic CVD process can occur, leading to uncontrolled film growth.

\subsection{Nature of the substrate surface}

The growth of a film by ALD takes place successively on the substrate surface (first cycles), on a surface made by both the substrate and the deposited material (following cycles), and finally on a surface made only of the ALD-grown material. Therefore, as the chemical composition of the surface 
varies with the number of cycles, the observed GPC is not the same during the initial growth of the ALD process. Three growth regimes can be identified, which depict the influence of the number of cycles on the GPC:

- Linear growth: the GPC is constant from the first ALD cycle. This can be the case of a process where the number of adsorption sites is constant, or a process where the steric hindrance of the precursor regulates the saturation;

- Growth assisted by the substrate: the GPC is higher during the first ALD cycles, possibly because the number of adsorption sites is higher at the substrate surface than on the deposited material;

- Growth inhibited by the substrate: the GPC is lower during the first ALD cycles, due to a lower number of adsorption sites at the substrate surface than at the deposited material. This phenomenon corresponds to the island growth, which is the one most commonly observed in ALD.

The nucleation, which corresponds to the first cycles of an ALD film growth, is therefore strongly influenced by the nature of the substrate and the process used. For example, a lot of research efforts have been dedicated to study the nucleation of ALD of oxides on graphene to prepare protective interfaces and supporting layers during graphene transfer. ${ }^{34-36}$ It is important to note that the different growth regimes observed on a given substrate offer the possibility to develop selective growth ALD processes, which represents a major asset of the ALD technique. ${ }^{37}$

ALD has been used to prepare a wide variety of nanomaterials, oxides, semiconductors and metals, in different morphologies such as thin films ${ }^{7,9,10,38}$ and nanoparticles. ${ }^{39,40}$ Furthermore, as novel applications of ALD emerged in areas such as membranes but also photovoltaics or flexible electronics, innovative approaches and reactors to integrate new processes, substrates and precursor delivery techniques have been developed (e.g. for temperature-sensitive supports). These include for examples energy-enhanced and spatial ALD schemes involving plasma, direct-write, atmospheric pressure, and roll-to-roll processing. ${ }^{41}$ In fact, the use of roll-to-roll processing would 
allow ALD to address many applications in a cost effective manner. For further detailed information about ALD basics and recent developments, the reader is referred to excellent reviews written in this area. ${ }^{7,8,45-49,9,10,27,38,41-44}$

\section{How to perform ALD on membrane substrates?}

ALD offers the possibility to grow films on various substrates with an excellent conformality coupled with a subnanometer thickness control, which makes this route very powerful to tune membrane material properties and achieve the control of their pore size and their interface engineering, even at large scale. By imparting pores with functional nanolayers, ALD coatings are able to improve the stability of membranes (e.g. towards steam or sulfur compounds), to make them biocompatible, to limit fouling phenomena and to enhance the overall system performance. ${ }^{13,14}$ However, before considering large scale application of ALD for membrane technologies, several points must be taken into consideration in order to perform ALD efficiently on these peculiar membrane substrates.

The immense majority of membranes is either based on ceramic or polymeric materials, and typically present porous structures with extremely high aspect ratio. This high aspect ratio is a key parameter to take into account when performing ALD on membrane substrates. To reach a conformal coating of pores with high aspect ratio and nanoscale dimensions, ALD process parameters have to be tuned. Large number of experimental and theoretical studies has been already performed to gain better understanding on the ALD chemistry taking place in high-aspect-ratio structures. ${ }^{50-54}$ In a standard ALD process, precursor molecules easily penetrate into macroscopic and microscopic pores through molecular flow. ${ }^{54-56}$ Two conditions only need to be fulfilled: the precursor doses must be sufficiently large to saturate each surface reaction, and its vapors must be exposed to the pore openings for a sufficient time. ${ }^{51}$

Mesoporous and microporous membrane materials such as ceramics and composites can present aspect ratios over 10000. Even if ALD allows for extremely conformal coatings, the deposition of films within these nanostructures is extremely challenging. However, impressively, ALD can be achieved 
on/in both mesoporous and microporous substrates. For example, mesoporous films with a tridimensional porous network built of nanoslabs with pore widths of 4-6 nm were successfully coated with ALD of $\mathrm{TiO}_{2} \cdot{ }^{57}$ Logically, ALD of $\mathrm{TiO}_{2}$ at the pore entrance resulted in a gradual decrease of the free diameter (available pore opening) when the film thickness increased. It is important to note that the combination of a fixed precursor exposure time and a narrowing of the pores may result in lower deposition at the bottom of the pores, since diffusional limitations can appear.

When considering ALD on even smaller pores such as micropores, the steric hindrance of the precursor molecules should be considered, as they may be larger than the pore entrance. ALD of $\mathrm{TiO}_{2}$ has also been carried out by the same group on a microporous membrane material with average pore size of $1 \mathrm{~nm}$ and a porosity of $\sim 40 \% .^{58}$ The diameter of the precursor molecules used for this particular process (Tetrakis(dimethylamino)titanium, TDMAT) is $\sim 0.7 \mathrm{~nm}$, and they could thus penetrate into the micropores in the first cycle. It has been observed that the increment of titanium loading per cycle became lower already during the first cycles, and not all micropores could be filled. In fact, 2-3 cycles were sufficient to shrink the pore size below the kinetic diameter of the TDMAT molecules, thus forbidding any further access within the pores. ${ }^{58}$

ALD of $\mathrm{Al}_{2} \mathrm{O}_{3}$ has been performed as well in both mesoporous and microporous substrates. The ALD coating was found to decrease both mesopores and micropores surface areas, which was mainly attributed to a coverage of the pore surfaces with $\mathrm{Al}_{2} \mathrm{O}_{3}$ (although a clogging of the pore entrances could also occur). ${ }^{54}$ Considering ALD deposition on/in such extreme high aspect ratios structures, there is a need for researchers to develop new chemistries for precursor molecules, in order to limit as much as possible the steric hindrance, while keeping surface reactivity and high vapor pressure. Another point to consider is the rapid occurrence of pore closure after a small number of ALD cycles, $^{59,60}$ leading to asymmetric deposition with the pore length and a decrease of membrane performance. When coating mesopores with $\mathrm{HfO}_{2}$ by $\mathrm{ALD}$, Dendooven et al. monitored the $\mathrm{Hf}$-uptake per ALD cycle using in situ X-Ray Fluorescence (XRF). ${ }^{60}$ Pore necks were no longer accessible for the 
Hf-precursor molecules after only 19 cycles. From then on, ALD continued on top of the coated mesoporous film (Figure 7).

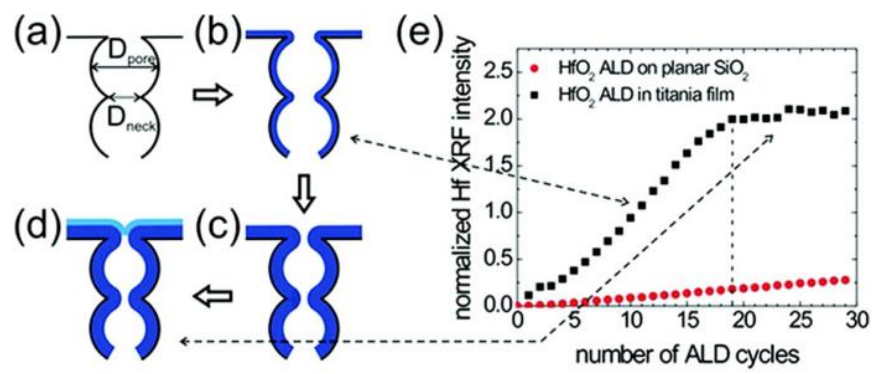

Figure 7: (a-d) Schematic representation of conformal ALD of $\mathrm{HfO}_{2}$ in titania mesopores. (e) In situ XRF during $\mathrm{HfO}_{2}$ ALD on either planar $\mathrm{SiO}_{2}$ substrate or mesoporous titania film: evolution of $\mathrm{Hf} \mathrm{L} \alpha$ (7.9 keV) peak area vs. the number of ALD cycles. As depicted in (d), the pores are no longer accessible for the Hf-precursor molecules and from then on, ALD film grows on top of the coated mesoporous film, as observed in the XRF spectra (e). Reproduced with permission from Chem. Mater. 24, 11, 1992 (2012). Copyright 2012 American Chemical Society.

In addition to the fact that the exposure times need to be considerably extended, this potential pore closure is a second reason for which ALD processes applied to meso/microporous membranes should be limited to a few cycles only. When considering pores at the nanoscale such as mesopores and micropores, the ALD process is governed by Knudsen diffusion. ${ }^{52,61}$ Gas molecules collide more frequently with the pore walls than with each other's, because the pore size is comparable to or smaller than the mean free path of the precursor and reactant molecules.

This Knudsen diffusion model can be used to predict the penetration depths in high aspect ratio substrates. The penetration depth of a coating prepared by ALD into a straight and narrow hole depends mainly on the process saturation behaviour, precursor partial pressure, exposure time, molecular mass, and process temperature. ${ }^{51}$ Gordon et al. developed a mathematical model based on the kinetics in order to determine the required precursor exposure time to conformally coat nanopores with defined aspect ratio. ${ }^{51}$ These diffusion processes have also been modeled by 
others, ${ }^{52,61,62}$ and the initial model has been completed by including the sticking probability of the precursor molecules to the substrate in order to achieve more realistic conditions. ${ }^{52}$

When considering practical ALD experiments, it is important to realize that high aspect ratio membranes require very large precursor and reactant exposure times. When using continuous flows in a typical viscous-flow reactor, these long exposure times are impractical because they rapidly empty the precursor container. Therefore, when performing ALD on/in porous membranes, exposure times have to be considerably extended in comparison with flat non-porous supports, but the viscous-flow ALD reactor should be operated in a quasi-static mode, ideally by closing the pump gate valve during the exposure steps.

Overall, when performing ALD on/in membranes presenting micropores and mesopores, the choice of the precursor chemistry and molecular dimension, the extended exposure and purge times, the quasi-static mode of the reactor, as well as the very limited number of cycles for microporous membranes, become crucial elements to achieve an efficient ALD process. ${ }^{51,52,54}$

The immense majority of commercial membranes are based on polymeric materials. For example polypropylene (PP), polyethyleneterephtalate (PET) and polyamide (PA) can be used for separative applications, from microfiltration to nanofiltration. ${ }^{63-65}$ Considering ALD on/in membrane supports based on organic polymeric materials, special care must be taken. The first obvious consideration is related to the ALD process temperature, which has to be lower than the polymer melting point (usually in the range $100-200^{\circ} \mathrm{C}$ ). In addition, as reviewed by Parsons and co-workers, ${ }^{66}$ it has been shown that during ALD on/in polymers, precursors often infiltrate and react with the support material; this might alter the support and even modify its mechanical properties. Extending the exposure time per cycle in the ALD process, further extent the reaction risk between the polymer and the precursor. ${ }^{66-72}$ Considered as a school case of $A L D$, the $A L D$ of $\mathrm{Al}_{2} \mathrm{O}_{3}$ from trimethylaluminium and water has been performed and studied on a wide variety of membrane material substrates, including polymers such as PP, PET and PA. 
Polypropylene does not present readily available active sites for growth initiation by ALD, and ALD of $\mathrm{Al}_{2} \mathrm{O}_{3}$ typically results in an intermixed polymer/inorganic interface layer. ${ }^{73}$ It has been found that the TMA precursor (and/or water) diffuses into the region near the top-surface of the polymer where it is kinetically trapped. During the second half-cycle, TMA reacts with water and nuclei are formed beneath or at the polymer surface. The depth of sub-surface growth as well as the extent of $\mathrm{H}_{2} \mathrm{O}$ reactant diffusion depend on both the substrate temperature and exposure time. ${ }^{66,70,71}$ The surface roughness and the polymer $/ \mathrm{Al}_{2} \mathrm{O}_{3}$ interface are strongly affected by this sub-surface growth, ${ }^{66,70}$ which has to be taken into account when the aim is to perform ALD to coat polymeric PP membrane pores. Figure 8 presents TEM images of a polymeric PP substrate after 100 ALD cycles of $\mathrm{Al}_{2} \mathrm{O}_{3}$, where the formation of sub-surface particles is clearly seen.
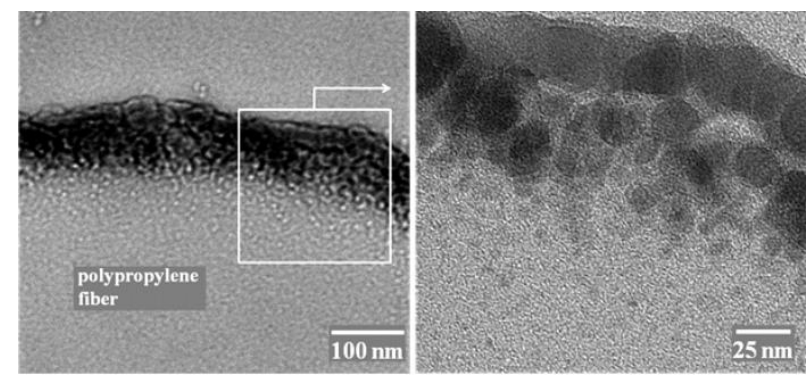

Figure 8: TEM views of polypropylene surface after $100 \mathrm{ALD} \mathrm{Al}_{2} \mathrm{O}_{3}$ cycles at $90{ }^{\circ} \mathrm{C}$, producing a graded polymer/inorganic interface and rough surface texture. The subsurface particles are visible underneath the continuous film. Reproduced with permission from Langmuir 26, 8239 (2010). Copyright 2010 American Chemical Society

In a recent comparative study, $\mathrm{ALD}$ of $\mathrm{Al}_{2} \mathrm{O}_{3}$ and $\mathrm{ZnO}$ have been performed on polymeric PET substrates at the same temperature $\left(90^{\circ} \mathrm{C}\right)$. The sub-surface growth was observed in both cases, and was found to generate new failure mode as the resulting films were delaminating. Interestingly, uniaxial tensile strain measurements revealed superior adhesive properties of $\mathrm{ZnO}$ films versus $\mathrm{Al}_{2} \mathrm{O}_{3}$ films. ${ }^{69}$ As expected, the characteristics of the ALD precursor (diethylzinc versus TMA) strongly affect the mechanical properties of the modified polymer. Polyamides are polymers presenting reactive 
groups, such as carbonyl and amine, which enable strong hydrogen bonding between neighboring chains. Infrared spectroscopy studies revealed that the TMA precursor exposure influences both groups, and that the reaction between TMA and the carbonyl or amine groups modify the initial strong hydrogen bonding. ${ }^{70}$ This could actually favor deeper TMA diffusion into the subsurface region, as the disruption of this hydrogen bonding might induce an opening of the polymeric chain network. The mechanical properties of the ALD-modified polyamide would in consequence be strongly affected as well. The modification of the mechanical properties and the risk of film delamination have also to be taken into account when performing ALD on porous polymer membrane substrates.

However, as film strength and adhesion play a crucial role in the performance of the functional membrane materials, several routes can be used to enhance the adhesion of ALD films and limit delamination issues. For example, Latella et al. obtained good results with a plasma pretreatment of the substrate. In fact, the water-plasma pretreatment plays an important role in the adhesion of the alumina film to polymers (PC), as evidenced by the reduced number of delamination sites and the threefold increase in the calculated interface fracture energy compared with the as-received surface. ${ }^{74,75}$ Preparing thin films as nanolaminates is another good strategy to obtain better adhesion. In fact, the hardness and adhesion of oxide nanolaminates is typically improved in comparison with its separated constituents. ${ }^{76}$

Finally, when considering ALD on/in polymers such as cellulose or PVA presenting a high density of initial reactive groups, the ALD reaction will be limited to the polymer top surface. Indeed the high density of initial reaction sites available permit fast growth of dense films. ${ }^{66}$ Therefore, if the aim is to maintain the initial porous structure of a polymer membranes and simply tune its pores surface properties by using ALD, such polymer materials with a high density of reactive sites should be chosen as supports.

Overall, the chemical reactions and mechanisms related to ALD on polymer substrates are strongly influenced by both the nature of the ALD precursor and the polymer chemistry. Thus, the ability to 
precisely control reactions between ALD precursors and polymer substrates would open new prospects for membrane science. For example, using asymmetric and composite membranes based on a stacking of layers with different materials and pore sizes, the ALD precursors could be chosen to react selectively with different parts of the structure, and convert the initial polymer into a new organic/inorganic material presenting properties defined by the selected ALD process parameters.

\section{Selected examples of ALD works for membrane applications}

\subsection{Pore diameter reduction for improved selectivity}

One of the most obvious benefits of ALD for membrane applications is that it effectively permits to reduce pores diameters and increase the aspect-ratio, hence improving membrane selectivity towards smaller species (shifting of the cut-off). Cameron et al. were the first to report the use of ALD to reduce pore diameters of mesoporous alumina membranes by applying ALD of $\mathrm{SiO}_{2}$ and $\mathrm{TiO}_{2}$. The $\mathrm{N}_{2}$ permeance measurements showed that the $\mathrm{SiO}_{2}$ and $\mathrm{TiO}_{2} \mathrm{ALD}$ layers gradually reduced the membrane pore diameter from its initial size of $50 \AA$ to molecular dimensions, and that gas transport through micropores was governed both by pore sizes and by the interactions of the transported species with the membrane material at the pore surface. ${ }^{77} \mathrm{Li}$ et al. used ceramic ultrafiltration membranes as substrates on which $\mathrm{Al}_{2} \mathrm{O}_{3}$ was deposited by ALD. The pore size of these ceramic membranes was easily tuned by modifying the number of ALD cycles. Many porous ceramic membranes were coated by ALD to improve their selectivity. ${ }^{14}$ For example, mesoporous silica membranes coated by ALD of $\mathrm{SiO}_{2}$ offer higher $p / o$-xylene selectivity. In fact, the separation of $p$ over o-xylene was improved from 1 to 2.1 after modification by ALD. ${ }^{78}$ Another example is the work of Tran et al., who coated $\gamma-\mathrm{Al}_{2} \mathrm{O}_{3}$ membranes with a thin film of $\mathrm{TiO}_{2}(10 \mathrm{~nm})$ by ALD and obtained attractive $\mathrm{H}_{2} / \mathrm{CO}_{2}$ gas separation factor after ALD, increasing from 2 to about 5.8 for a $\mathrm{H}_{2} / \mathrm{CO}_{2}$ mixture at $450 K .^{79}$ 


\subsection{Surface hydrophilization for water filtration:}

Since most of the polymeric membranes materials such as PP or PTFE are chemically relatively inert and present non-polar hydrophobic surfaces, they are not optimal for water filtration applications. The membrane interface engineering allowed by ALD permits to gain control over the wettability of the membrane surface, as it can be used to coat the pore surface with a selected hydrophilic material. ALD has been therefore used to perform the hydrophobic-to-hydrophilic transition of different membrane surfaces. For example, ALD of $\mathrm{Al}_{2} \mathrm{O}_{3}, \mathrm{ZnO}$ or $\mathrm{TiO}_{2}$ have been performed on PTFE and PVDF membranes and allowed for the successful hydrophilization of their surfaces. ${ }^{80-84}$ Water contact angle measurements revealed that the hydrophobic surface gradually turned to be near superhydrophilic with the increment of ALD cycles. As a direct consequence of this novel surface hydrophilicity, one of the most attractive functional membrane property offered by ALD is therefore the enhancement of anti-fouling properties (or at least fouling mitigation). Indeed, many studies reported that membranes coated with ALD of oxides offer enhanced pollutant retention with moderate flux loss thanks to the hydrophilic nature of the deposited oxide. ${ }^{84-86}$ For example, when applying a $\mathrm{TiO}_{2}$ coating by ALD, the modified membranes presented both an increase of the pure water flux (by more than 150\%) and higher pollutant retention compared to the original unmodified membrane. ${ }^{81}$ In addition, the low surface roughness obtained after ALD coating (smoothing effect) also helps achieving low fouling (slippage effect) and high liquid permeability. ${ }^{87}$

\subsection{Pore diameter reduction and surface charge regulation for biosensing:}

Nanopore-based devices provide single-molecule detection and analytical capabilities that open many prospects in the field of biosensing. Indeed, the nanopore provides a highly confined space in which molecules such as single nucleic acid polymers can be analyzed at high throughput by a variety of means ${ }^{88}$ The transport of ions and biomolecules through nanochannels can be regulated by the channel diameter and its surface charge, both of which can be tailored by ALD. Thus, ALD can permit to achieve innovative fundamental studies in membrane science, and has the potential to become a 
novel and efficient route to tailor nanopore-based biosensing devices. ${ }^{89-92}$ Different ALD materials have been prepared for tuning such nanochannels. Whereas ALD of boron nitride (BN) enabled to increase the surface charge of nanopores dramatically, ${ }^{11}$ ALD of $\mathrm{SiO}_{2}$ was found to reduce the effective fixed charge and alleviate the coulombic barrier effect to cation transport. ${ }^{93}$ Lepoitevin and co-workers used ALD to tailor polymeric track-etched nanopores with $\mathrm{ZnO}$ or $\mathrm{Al}_{2} \mathrm{O}_{3}$ films. The objective was first to reduce pore dimensions, but also to obtain smoother surfaces and functionalize them with amine groups in order to achieve smart nanopores able to mimic biological channels. ${ }^{92,94}$ All these studies confirmed the facts that ALD not only allows reducing both pore size and pore volume, but also affects the electric charge fixed on the membrane pore surface, which opens new horizons for biosensing applications such as DNA sequencing and drug delivery devices.

\section{Conclusions}

Atomic layer deposition (ALD) is a scalable technology allowing the deposition of ultrathin films in porous structures with a precise growth control at the nanometer scale, a high uniformity as well as an excellent conformality. It represents therefore a unique and remarkable route, as it offers nanoengineering capabilities and a versatility that conventional methods cannot meet. ALD is currently used for very challenging thin-film deposition applications and opens novel prospects for membrane science, as this route has the ability to coat pores at the nanoscale with functional layers. This tutorial first presented the basic concepts of membrane science and ALD technology. The nomenclature, the main concepts of established membrane physics, and the theories behind the separation mechanisms were given. The morphology and the most common materials used for their fabrication have been presented as well. The fundamentals of ALD were then summarized. The impact of the surface chemistry, of the duration of the cycle steps and of the temperature applied have been described, in order to give the reader the basics required to develop an ALD process.

The tutorial focused on explaining how to reach the conformal coating of pores presenting dimensions at the nanoscale such as those present in nanoporous membranes. In fact, the ALD 
processes have to be tuned for these specific membrane substrates. Overall, the choice of the precursor chemistry, the extended exposures and purge times, but also the quasi-static mode of the reactor as well as a very small number of cycles for microporous membranes become essential elements. Considering ALD on membrane supports based on organic polymeric materials, the temperature of the process and the diffusion of the precursors within the polymer matrix itself have to be considered as well, as a sub-surface ALD growth was observed for various polymeric substrates. As illustrated in some selected examples, the technology has allowed obtaining membrane pores with chosen diameters and aspect ratios. ALD coatings often increased the hydrophilicity of the pores surface, and improved the overall performance of inorganic, organic, and composite membranes. In fact, thanks to the hydrophilic nature of the deposited ALD layers, various studies reported that membranes coated with ALD permitted the mitigation of fouling phenomena.

To conclude, we believe that the recent advances in the understanding of ALD mechanisms in highly porous structures, including in organic polymeric materials will boost the development of more efficient processes in the near future, which could lead to the fabrication of membranes with enhanced permeability, selectivity, and durability.

\section{Acknowledgements:}

The authors thank the French National Research Agency (ANR, program MeNiNA - ANR-17-CE090049) for funding. The support of the COST Action "HERALD", a European cooperation program, is also acknowledged. 


\section{References}

${ }^{1}$ R.W. Baker, Membrane Technology and Applications (John Wiley and Sons Ltd, 2004).

${ }^{2}$ R.G. Grant, Mater. Manuf. Process. 4, 483 (1989).

${ }^{3}$ A.L. Zydney, AIChE J. 41, 2343 (1995).

${ }^{4}$ E. Drioli, L. Giorno, and E. Fontananova, Comprehensive Membrane Science and Engineering (Elsevier, 2017).

${ }^{5}$ J. Mulder, Basic Principles of Membrane Technology (Springer Science \& Business Media, 2012).

${ }^{6}$ J. Caro, M. Noack, P. Kölsch, and R. Schäfer, Microporous Mesoporous Mater. 38, 3 (2000).

${ }^{7}$ S.M. George, Chem. Rev. 110, 111 (2010).

${ }^{8}$ R.L. Puurunen, J. Appl. Phys. 97, 9 (2005).

${ }^{9}$ M. Ritala and M. Leskela, in Handb. Thin Film Mater. (2001), pp. 103-159.

${ }^{10}$ M. Leskelä and M. Ritala, Thin Solid Films 409, 138 (2002).

${ }^{11}$ M. Weber, B. Koonkaew, S. Balme, I. Utke, F. Picaud, I. latsunskyi, E. Coy, P. Miele, and M. Bechelany, ACS Appl. Mater. Interfaces 9, 16669 (2017).

${ }^{12}$ P.E. Petrochenko, G. Kumar, W. Fu, Q. Zhang, J. Zheng, C. Liang, P.L. Goering, and R.J. Narayan, J. Biomed. Nanotechnol. 11, 2275 (2015).

${ }^{13}$ H.-C. Yang, R.Z. Waldman, Z. Chen, and S.B. Darling, Nanoscale 10, 20505 (2018).

${ }^{14}$ M. Weber, A. Julbe, A. Ayral, P. Miele, M. Bechelany , Chem. Mater. 30, 7368 (2018).

${ }^{15}$ M. Thommes, K. Kaneko, A. V Neimark, J.P. Olivier, F. Rodriguez-Reinoso, J. Rouquerol, and K.S.W. Sing, Pure Appl. Chem. 87, 1051 (2015).

${ }^{16}$ P. AIMAR, P. BACCHIN, and A. MAUREL, (2010).

${ }^{17}$ C.J. Davey, Z.-X. Low, R.H. Wirawan, and D.A. Patterson, J. Memb. Sci. 526, 221 (2017).

${ }^{18}$ E. Matthiasson and B. Sivik, Desalination 35, 59 (1980).

${ }^{19}$ A. Giacobbo, A. Moura Bernardes, M. Filipe Rosa, and M. de Pinho, Membranes (Basel). 8, 46 (2018).

${ }^{20}$ B. Liu, F. Qu, H. Liang, B. Van der Bruggen, X. Cheng, H. Yu, G. Xu, and G. Li, Water Res. 112, 83 
(2017).

${ }^{21}$ A. Julbe, M. Drobek, and A. Ayral, Curr. Opin. Chem. Eng. 24, (2019).

${ }^{22}$ A.A. Malygin, V.E. Drozd, A.A. Malkov, and V.M. Smirnov, Chem. Vap. Depos. 21, 216 (2015).

${ }^{23}$ R.L. Puurunen, Chem. Vap. Depos. 20, 332 (2014).

${ }^{24}$ E. Ahvenniemi, A.R. Akbashev, S. Ali, M. Bechelany, M. Berdova, S. Boyadjiev, D.C. Cameron, R.

Chen, M. Chubarov, and V. Cremers, J. Vac. Sci. Technol. A Vacuum, Surfaces, Film. 35, 10801 (2017).

${ }^{25}$ I.J. Raaijmakers, ECS Trans. 41, 3 (2011).

${ }^{26}$ O. Graniel, M. Weber, S. Balme, P. Miele, M. Bechelany, Biosens. Bioelectron. 122, 147 (2018).

${ }^{27}$ R.W. Johnson, A. Hultqvist, and S.F. Bent, Mater. Today 17, 236 (2014).

${ }^{28}$ R.K. Ramachandran, C. Detavernier, and J. Dendooven, in Nanotechnol. Catal. (Wiley-VCH Verlag GmbH \& Co, 2017), pp. 335-358.

${ }^{29}$ J.A. Van Delft, D. Garcia-Alonso, and W.M.M. Kessels, Semicond. Sci. Technol. 27, 074002 (2012).

${ }^{30}$ T. Hatanpää, M. Ritala, and M. Leskelä, Coord. Chem. Rev. 257, 3297 (2013).

${ }^{31}$ P. Violet, E. Blanquet, D. Monnier, I. Nuta, and C. Chatillon, Surf. Coatings Technol. 204, 882 (2009).

${ }^{32}$ E. Langereis, S.B.S. Heil, H.C.M. Knoops, W. Keuning, M.C.M. Van de Sanden, and W.M.M. Kessels, J. Phys. D. Appl. Phys. 42, 73001 (2009).

${ }^{33}$ N. Leick, J.W. Weber, A.J.M. Mackus, M.J. Weber, M.C.M. Van de Sanden, and W.M.M. Kessels, J. Phys. D. Appl. Phys. 49, 115504 (2016).

${ }^{34}$ S.C. O’Hern, D. Jang, S. Bose, J.-C. Idrobo, Y. Song, T. Laoui, J. Kong, and R. Karnik, Nano Lett. 15, 3254 (2015)

${ }^{35}$ A.I. Aria, K. Nakanishi, L. Xiao, P. Braeuninger-Weimer, A.A. Sagade, J.A. Alexander-Webber, and S. Hofmann, ACS Appl. Mater. Interfaces 8, 30564 (2016).

${ }^{36}$ A. Cabrero-Vilatela, J.A. Alexander-Webber, A.A. Sagade, A.I. Aria, P. Braeuninger-Weimer, M.-B. Martin, R.S. Weatherup, and S. Hofmann, Nanotechnology 28, 485201 (2017).

${ }^{37}$ A.J.M. Mackus, M.J.M. Merkx, and W.M.M. Kessels, Chem. Mater. (2018).

${ }^{38}$ G.N. Parsons, S.M. George, and M. Knez, Mrs Bull. 36, 865 (2011). 
${ }^{39}$ M.J. Weber, A.J.M. MacKus, M.A. Verheijen, C. van der Marel, and W.M.M. Kessels, Chem. Mater. 24, 2973 (2012).

${ }^{40}$ M.J. Weber, M.A. Verheijen, A.A. Bol, and W.M.M. Kessels, Nanotechnology 26, 094002 (2015).

${ }^{41}$ W.M.M. Kessels and M. Putkonen, MRS Bull. 36, 907 (2011).

${ }^{42}$ H. Van Bui, F. Grillo, and J.R. van Ommen, Chem. Commun. 53, 45 (2017).

${ }^{43}$ H. Kim, H.B.R. Lee, and W.J. Maeng, Thin Solid Films 517, 2563 (2009).

${ }^{44}$ J.S. Ponraj, G. Attolini, and M. Bosi, Crit. Rev. Solid State Mater. Sci. 38, 203 (2013).

${ }^{45}$ B.B. Lakshmi, C.J. Patrissi, and C.R. Martin, Chem. Mater. 9, 2544 (1997).

${ }^{46}$ V. Miikkulainen, M. Leskelä, M. Ritala, and R.L. Puurunen, J. Appl. Phys. 113, 2 (2013).

${ }^{47}$ H.C.M. Knoops, S.E. Potts, A.A. Bol, and W.M.M. Kessels, in Handb. Cryst. Growth (Elsevier, 2015), pp. $1101-1134$.

${ }^{48}$ M. Leskelä and M. Ritala, Angew. Chemie - Int. Ed. 42, 5548 (2003).

${ }^{49}$ M. Ritala and M. Leskela, Handb. Thin Film Mater. Vol. 1 Depos. Process. Thin Film. 103 (2002).

${ }^{50}$ T. Keuter, N.H. Menzler, G. Mauer, F. Vondahlen, R. Vaßen, and H.P. Buchkremer, J. Vac. Sci. Technol. A Vacuum, Surfaces, Film. 33, 01 A104 (2015).

${ }^{51}$ R.G. Gordon, D. Hausmann, E. Kim, and J. Shepard, Chem. Vap. Depos. 9, 73 (2003).

52 J. Dendooven, D. Deduytsche, J. Musschoot, R.L. Vanmeirhaeghe, and C. Detavernier, J. Electrochem. Soc. 156, 63 (2009).

${ }^{53}$ J. Dendooven, K. Devloo-Casier, E. Levrau, R. Van Hove, S. Pulinthanathu Sree, M.R. Baklanov, J.A. Martens, and C. Detavernier, Langmuir 28, 3852 (2012).

${ }^{54}$ C. Detavernier, J. Dendooven, S. Pulinthanathu Sree, K.F. Ludwig, and J.A. Martens, Chem. Soc. Rev. 40, $5242(2011)$.

${ }^{55}$ P. Chen, T. Mitsui, D.B. Farmer, J. Golovchenko, R.G. Gordon, and D. Branton, Nano Lett. 4, 1333 (2004).

${ }^{56}$ J.W. Elam, D. Routkevitch, P.P. Mardilovich, and S.M. George, Chem. Mater. 15, 3507 (2003).

${ }^{57}$ S.P. Sree, J. Dendooven, D. Smeets, D. Deduytsche, A. Aerts, K. Vanstreels, M.R. Baklanov, J.W. Seo, 
K. Temst, and A. Vantomme, J. Mater. Chem. 21, 7692 (2011).

${ }^{58}$ J. Dendooven, S. Pulinthanathu Sree, K. De Keyser, D. Deduytsche, J.A. Martens, K.F. Ludwig, and C. Detavernier, J. Phys. Chem. C 115, 6605 (2011).

${ }^{59}$ Y.-B. Jiang, N. Liu, H. Gerung, J.L. Cecchi, and C.J. Brinker, J. Am. Chem. Soc. 128, 11018 (2006).

${ }^{60}$ J. Dendooven, B. Goris, K. Devloo-Casier, E. Levrau, E. Biermans, M.R. Baklanov, K.F. Ludwig, P. Van Der Voort, S. Bals, and C. Detavernier, Chem. Mater. 24, 1992 (2012).

${ }^{61}$ M. Rose, J.W. Bartha, and I. Endler, Appl. Surf. Sci. 256, 3778 (2010).

${ }^{62}$ A.M. Lankhorst, B.D. Paarhuis, H.J.C.M. Terhorst, P.J.P.M. Simons, and C.R. Kleijn, Surf. Coatings Technol. 201, 8842 (2007).

${ }^{63}$ H.-Y. Yu, J. Zhou, J.-S. Gu, and S. Yang, J. Memb. Sci. 364, 203 (2010).

${ }^{64}$ H. Qian, J. Zheng, and S. Zhang, Polymer (Guildf). 54, 557 (2013).

${ }^{65}$ P. Hamerli, T. Weigel, T. Groth, and D. Paul, Biomaterials 24, 3989 (2003).

${ }^{66}$ G.N. Parsons, S.E. Atanasov, E.C. Dandley, C.K. Devine, B. Gong, J.S. Jur, K. Lee, C.J. Oldham, Q. Peng, and J.C. Spagnola, Coord. Chem. Rev. 257, 3323 (2013).

${ }^{67}$ S.-M. Lee, E. Pippel, U. Gösele, C. Dresbach, Y. Qin, C.V. Chandran, T. Bräuniger, G. Hause, and M. Knez, Science (80-. ). 324, 488 (2009).

${ }^{68}$ N. Pinna and M. Knez, Atomic Layer Deposition of Nanostructured Materials (John Wiley \& Sons, 2012).

${ }^{69}$ V. Chawla, M. Ruoho, M. Weber, A.A. Chaaya, A.A. Taylor, C. Charmette, P. Miele, M. Bechelany, J. Michler, and I. Utke, Nanomaterials 9, 88 (2019).

${ }^{70}$ J.C. Spagnola, B. Gong, S.A. Arvidson, J.S. Jur, S.A. Khan, and G.N. Parsons, J. Mater. Chem. 20, 4213 (2010).

${ }^{71}$ B. Gong and G.N. Parsons, J. Mater. Chem. 22, 15672 (2012).

${ }^{72}$ C.Z. Leng and M.D. Losego, Mater. Horizons 4, 747 (2017).

${ }^{73}$ J.S. Jur, J.C. Spagnola, K. Lee, B. Gong, Q. Peng, and G.N. Parsons, Langmuir 26, 8239 (2010).

${ }^{74}$ B.A. Latella, G. Triani, and P.J. Evans, Scr. Mater. 56, 493 (2007). 
${ }^{75}$ B.A. Latella, G. Triani, Z. Zhang, K.T. Short, J.R. Bartlett, and M. Ignat, Thin Solid Films 515, 3138 (2007).

${ }^{76}$ O.M.E. Ylivaara, L. Kilpi, X. Liu, S. Sintonen, S. Ali, M. Laitinen, J. Julin, E. Haimi, T. Sajavaara, and H. Lipsanen, J. Vac. Sci. Technol. A Vacuum, Surfaces, Film. 35, 01B105 (2017).

${ }^{77}$ M.A. Cameron, I.P. Gartland, J.A. Smith, S.F. Diaz, and S.M. George, Langmuir 16, 7435 (2000).

${ }^{78}$ B.A. McCool and W.J. DeSisto, Ind. Eng. Chem. Res. 43, 2478 (2004).

${ }^{79}$ T.H.Y. Tran, W.G. Haije, V. Longo, W.M.M. Kessels, and J. Schoonman, J. Memb. Sci. 378, 438 (2011).

${ }^{80}$ Q. Xu, Y. Yang, X. Wang, Z. Wang, W. Jin, J. Huang, and Y. Wang, J. Memb. Sci. 415, 435 (2012).

${ }^{81}$ Q. Xu, Y. Yang, J. Yang, X. Wang, Z. Wang, and Y. Wang, J. Memb. Sci. 443, 62 (2013).

${ }^{82}$ P. Juholin, M.-L. Kääriäinen, M. Riihimäki, R. Sliz, J.L. Aguirre, M. Pirilä, T. Fabritius, D. Cameron, and R.L. Keiski, Sep. Purif. Technol. 192, 69 (2018).

${ }^{83}$ N. Li, J. Zhang, Y. Tian, J. Zhang, W. Zhan, J. Zhao, Y. Ding, and W. Zuo, J. Memb. Sci. 514, 241 (2016).

${ }^{84}$ H.-C. Yang, Y. Xie, H. Chan, B. Narayanan, L. Chen, R.Z. Waldman, S.K.R.S. Sankaranarayanan, J.W. Elam, and S.B. Darling, ACS Nano 12, 8678 (2018).

${ }^{85}$ N. Li, Y. Tian, J. Zhao, J. Zhang, L. Kong, J. Zhang, and W. Zuo, J. Memb. Sci. 548, 470 (2018).

${ }^{86}$ Q. Wang, X. Wang, Z. Wang, J. Huang, and Y. Wang, J. Memb. Sci. 442, 57 (2013).

${ }^{87}$ J. Nikkola, J. Sievänen, M. Raulio, J. Wei, J. Vuorinen, and C.Y. Tang, J. Memb. Sci. 450, 174 (2014).

${ }^{88}$ D. Branton, D.W. Deamer, A. Marziali, H. Bayley, S.A. Benner, T. Butler, M. Di Ventra, S. Garaj, A. Hibbs, and X. Huang, in Nanosci. Technol. A Collect. Rev. from Nat. Journals (World Scientific, 2010), pp. 261-268.

${ }^{89}$ M. Lepoitevin, G. Nguyen, M. Bechelany, E. Balanzat, J.-M. Janot, and S. Balme, Chem. Commun. 51, 5994 (2015).

${ }^{90}$ S. Cabello-Aguilar, S. Balme, A.A. Chaaya, M. Bechelany, E. Balanzat, J.-M. Janot, C. PochatBohatier, P. Miele, and P. Dejardin, Nanoscale 5, 9582 (2013). 
${ }^{91}$ S. Balme, F. Picaud, M. Manghi, J. Palmeri, M. Bechelany, S. Cabello-Aguilar, A. Abou-Chaaya, P. Miele, E. Balanzat, and J.M. Janot, Nat. Publ. Gr. (2015).

${ }^{92}$ M. Lepoitevin, T. Ma, M. Bechelany, J.-M. Janot, and S. Balme, Adv. Colloid Interface Sci. 250, 195 (2017).

${ }^{93}$ V. Romero, V. Vega, J. García, R. Zierold, K. Nielsch, V.M. Prida, B. Hernando, and J. Benavente, ACS Appl. Mater. Interfaces 5, 3556 (2013).

${ }^{94}$ A. Abou Chaaya, M. Le Poitevin, S. Cabello-Aguilar, S. Balme, M. Bechelany, S. Kraszewski, F. Picaud, J. Cambedouzou, E. Balanzat, J.-M. Janot, A.A. Chaaya, M. Le Poitevin, S. Cabello-Aguilar, S. Balme, M. Bechelany, S. Kraszewski, F. Picaud, J. Cambedouzou, E. Balanzat, J.-M. Janot, T. Thami, P. Miele, and P. Dejardin, J. Phys. Chem. C 117, 15306 (2013). 